\title{
A Novel Dual-Electrode Plug to Achieve Intensive Electric Field for High Performance Ignition
}

\author{
Chih-Lung Shen, Jye-Chau Su, and Tsair-Chun Liang \\ Department of Electronic Engineering, National Kaohsiung First University of Science and Technology, \\ Kaohsiung City 82445, Taiwan
}

Correspondence should be addressed to Chih-Lung Shen; clshen@ccms.nkfust.edu.tw

Received 10 September 2013; Accepted 13 October 2013

Academic Editor: Teen-Hang Meen

Copyright (c) 2013 Chih-Lung Shen et al. This is an open access article distributed under the Creative Commons Attribution License, which permits unrestricted use, distribution, and reproduction in any medium, provided the original work is properly cited.

\begin{abstract}
A thorough analysis of electric field is carried out so as to verify that a novel dual-electrode plug can build intensive electric field and can improve the main drawbacks of feeble electric field and low ignition efficiency of the traditional plug. With intensive electric field, the proposed novel plug can achieve high performance ignition, resulting in fuel saving and exhaust reduction. Gauss law is applied for electric field analysis to show that intensive electric field can be built by the novel plug. Then, according to Faraday law a lower-voltage ignition feature accomplished by the plug is discussed. Compared with traditional plug, the novel dual-electrode plug has the following advantages. (1) Much higher energy density is built between the plug electrodes, lowering ignition voltage requirement. (2) Electromagnetic interference (EMI) problem caused by high ignition voltage is readily resolved. (3) Ignition time delay can be improved. (4) The feature to save fuel consuming is achieved. (5) The exhaust of CO and HC is reduced significantly. Practical measurements are fulfilled to validate the electric field analysis and to demonstrate the features of the proposed dualelectrode plug.
\end{abstract}

\section{Introduction}

Recently, the world is facing the threat of global warming due to the heavy use of fossil fuels and other greenhouse gases which result in a substantial increase of carbon dioxide. There are $24 \%$ of carbon dioxide emissions across the world, which is produced by the transportation tools. Mostly, it is produced from motor vehicles because of the use of fossil fuel [1]. In order to reduce the emission pollution from transportation tools, one has to understand how an electrical field is built by the spark plug and how a time delay is caused by the spark plug. In general, the operation of a vehicle engine can be divided into four steps: (1) intake, (2) compression, (3) explosive combustion, and (4) exhaust.

In an engine ignition cycle $[2,3]$, the engine power comes from which the explosion of the spark plug ignites the compressed mixed gas, and then the piston pushes the crankshaft rotation to generate power output. When the cross-section of the electrodes of the spark plug is too large, the spark arc will not concentrate at a point easily. Thus, this is difficult to start the engine and is prone to cause an incomplete combustion, resulting in exhaust pollution. Moreover, it needs a higher ignition voltage to produce a critical electrical field for the plug. A higher ignition voltage will cause a more serious EMI problem. Besides, if a plug needs a high ignition voltage, it has to take longer time for voltage accumulation, leading to time delay for igniting. Figure 1 illustrates that an optimal igniting time locates at the 10 degrees of crankshaft.

Therefore, the establishment of the ignition voltage and electric field [4-6] for a spark plug is very important. In this paper, with the application of Maxwell equations $[7,8]$, we propose a dual-electrode enhanced electric field plug for combustion engines. The proposed plug not only can build a more intensive ignition electric field and can produce a spark arc in time.

\section{The Proposed Plug Structure}

To ignite the proposed spark plug, a corresponding block diagram of the ignition system is shown in Figure 2, in which 


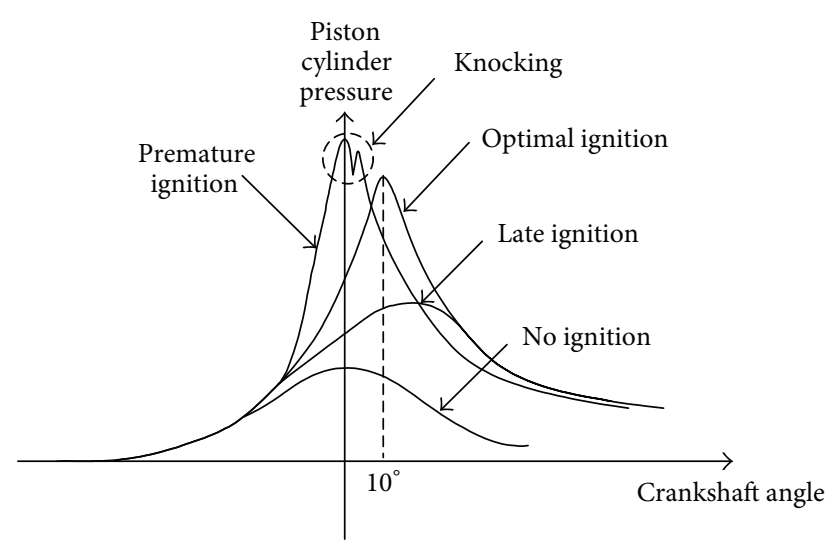

Top dead point

Figure 1: The relationship between crankshaft position and the combustion chamber pressure.

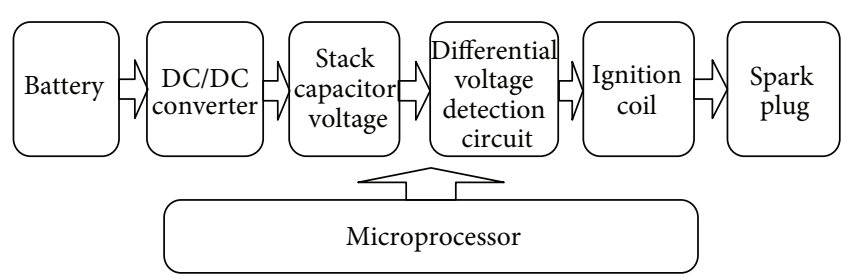

FIGURE 2: A block diagram of electronic ignition system.

the DC/DC converter can be implemented by a switch-mode converter [9-15]. In this paper, the flyback-type converter is adopted to fulfill high voltage generation. In the following, we will deal with the electric field analysis and ignition voltage discussion.

\subsection{Principle of Dual-Electrode Plug with Enhanced Electric} Field. Figure 3 illustrates the structure of the output of an ignition system. According to Ampere theorem, one can know that charges will flow to the spark plug electrodes and then build an electrical field. When the electric field between the spark plug electrodes reaches the critical electrical field $E_{C}$, charges release energy and produce arc sparkle to ignite mixed gas for generating power [16]. In addition, the current and output charge of a high voltage ignition coil at each ignition time interval can be expressed as follows:

$$
\Delta q=i(t) \Delta t
$$

where $\Delta q$ is the total charge supplied to the plug.

\subsection{Critical Electric Field Built by Traditional Plug. Figure 4} shows the structure of a traditional spark plug, in which a Gaussian cylindrical shell is selected. The positive electrode is placed at the middle of the spark plug electrodes. In Figure $4, A_{1}$ is the cross-section of the positive electrode, $V_{i}$ is the voltage of the positive electrode, $V_{f}$ is the voltage of the negative electrode, $d$ is the distance between the plug

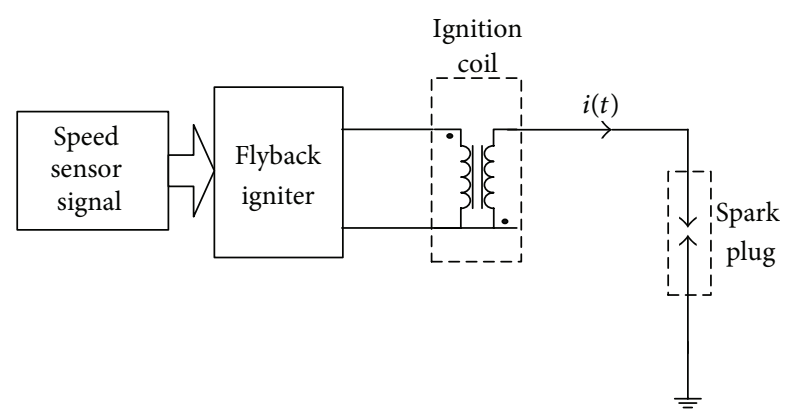

Figure 3: A simplified diagram to express the structure of the output of the ignition system.

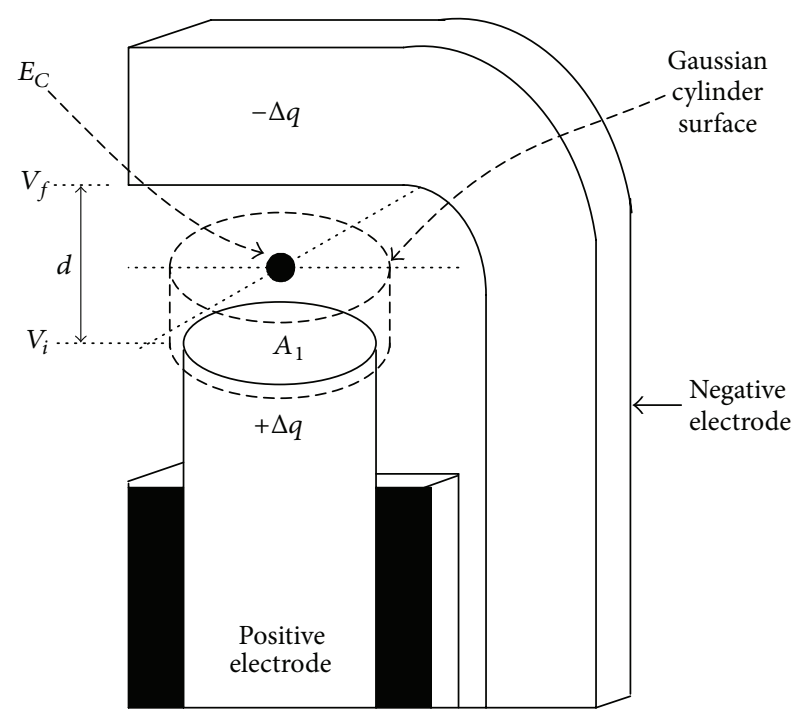

FIgURE 4: The structure of the traditional spark plug.

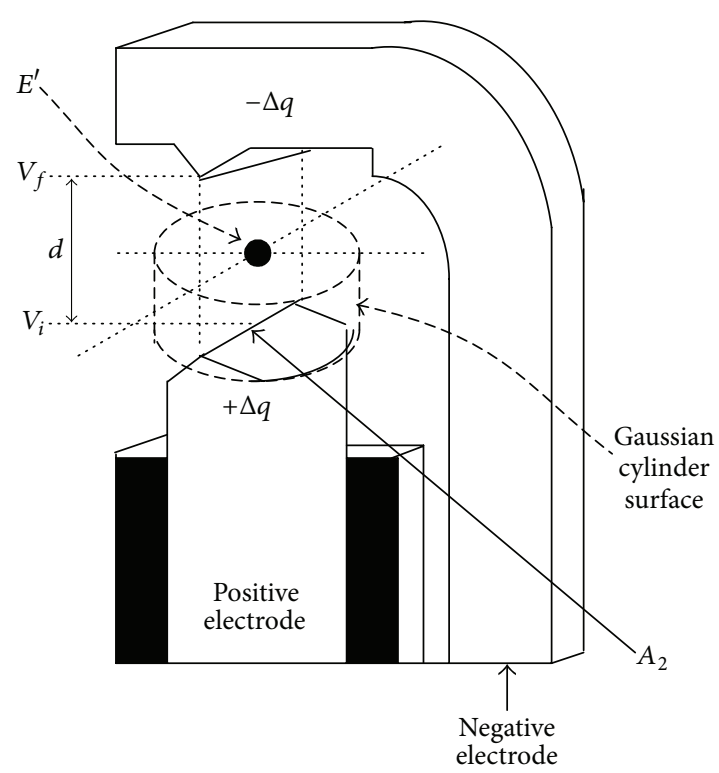

FIGURE 5: The structure of the proposed spark plug. 


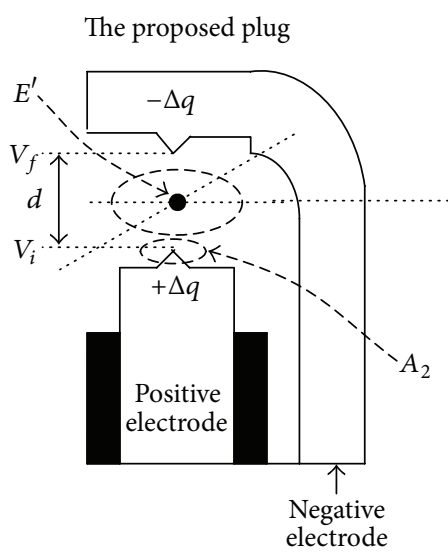

(a)
The traditional plug

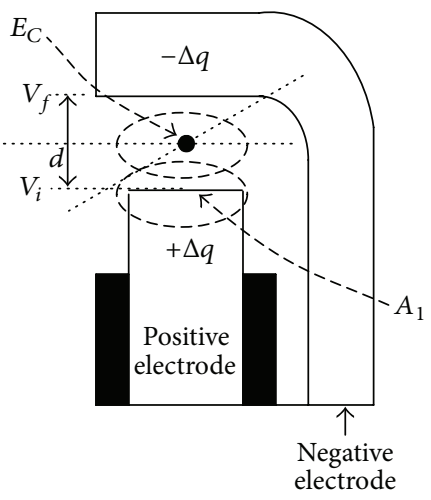

(b)

FIgURE 6: The side views of the proposed plug (a) and the traditional plug (b).

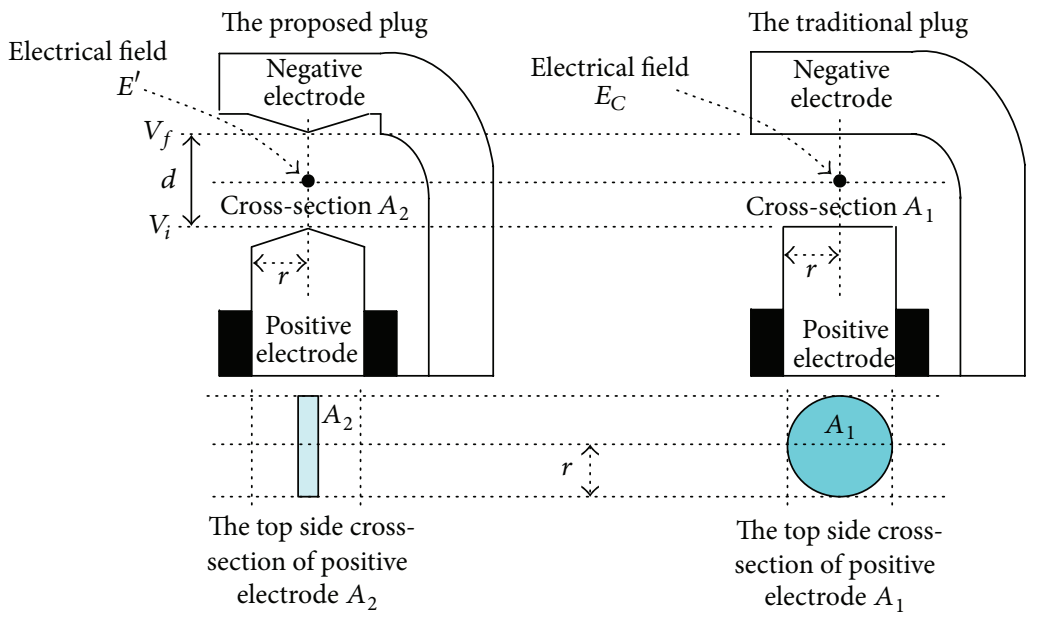

(a)

(b)

FIGURE 7: Expressing the key parameters of the proposed plug (a) and the traditional one (b).

electrodes, and $-\Delta q$ is the induced charge by $+\Delta q$. A critical electric field, $E_{C}$, is calculated as follows:

$$
\varepsilon_{0} \oint \vec{E} \cdot d \vec{A}=q
$$

where $\varepsilon_{0}$ is the permittivity of free space. The critical electrical field $E_{C}$ established between the two electrodes is

$$
E_{C}=\frac{\Delta q}{\varepsilon_{0} A_{1}} .
$$

From Faraday law, one can obtain

$$
\oint \vec{E} \cdot d \vec{s}=-\frac{d \Phi_{B}}{d t}=-V .
$$

The ignition voltage established between the two electrodes is

$$
\oint \vec{E}_{C} \cdot d \vec{s}=E_{C} d=-V_{1}
$$

where $V_{1}$ is determined by

$$
V_{1}=-E_{C} d=-\frac{d \Delta q}{\varepsilon_{0} A_{1}} .
$$

According to (3) and (6), if the cross-section of the spark plug electrodes, $A_{1}$, is reduced without changing the electrodes distance, the ignition electrical field will be established faster.

2.3. Electric Field Built by Proposed Plug. Figure 5 shows the structure of the proposed spark plug, in which the crosssection of the spark plug electrodes, $A_{2}$, is reduced as a shape of sharp knife, and the positive electrode faces the negative electrode with their sharp end. With the same way, a Gaussian cylindrical shell is selected and an electrical field, $E^{\prime}$, is calculated as

$$
E^{\prime}=\frac{\Delta q}{\varepsilon_{0} A_{2}} .
$$




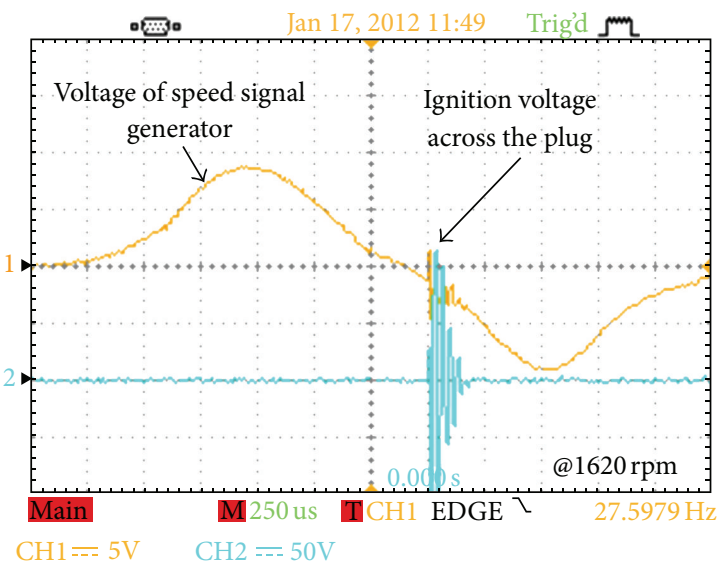

(upper trace: $5 \mathrm{~V} /$ div, lower trace: $5 \mathrm{kV} /$ div, time: $250 \mu \mathrm{s} / \mathrm{div}$ )

(a)

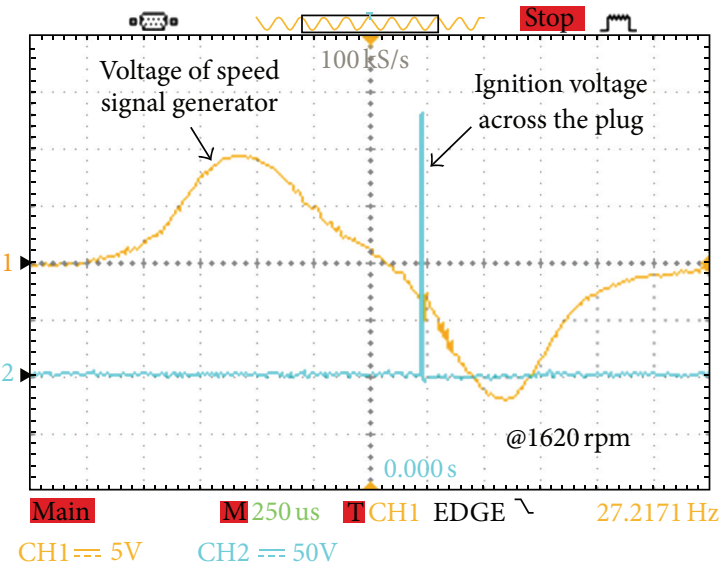

(upper trace: $5 \mathrm{~V} /$ div, lower trace: $5 \mathrm{kV} /$ div, time: $250 \mu$ s/div)

(b)

FIgURE 8: The waveforms of ignition timing under the speed of about $1620 \mathrm{rpm}$ : (a) traditional plug and (b) the proposed plug.

From Faraday law, the relationship holds

$$
\oint \vec{E} \cdot d \vec{s}=-\frac{d \Phi_{B}}{d t}=-V .
$$

The ignition voltage that is established between the two electrodes is

$$
\oint \vec{E}^{\prime} \cdot d \vec{s}=E^{\prime} d=-V_{2}
$$

where the $V_{2}$ can be calculated by

$$
V_{2}=-E^{\prime} d=-\frac{d \Delta q}{\varepsilon_{0} A_{2}}
$$

2.4. Comparisons of the Electric Field and Ignition Voltage. The side views of the proposed plug and traditional plug are placed in line horizontally in order to distinguish the magnitude of key parameters. Figure 6 shows the side views. The electric fields in the spark plug of traditional plug and the

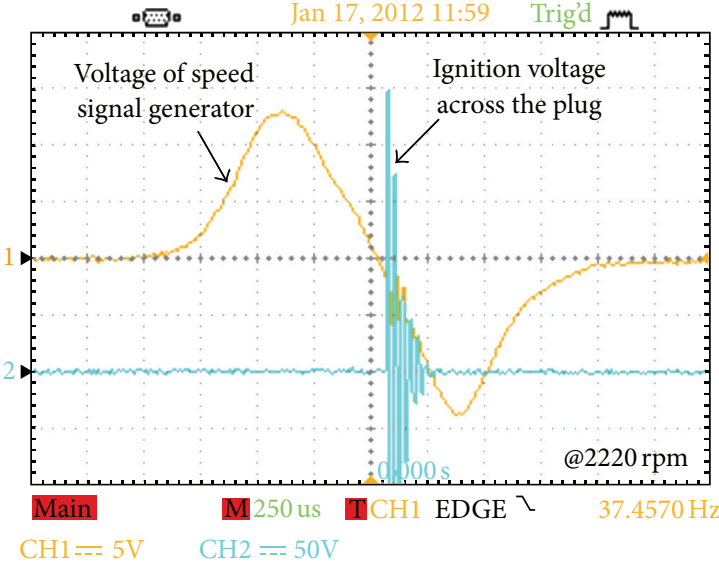

(upper trace: $5 \mathrm{~V} /$ div, lower trace: $5 \mathrm{kV} /$ div, time: $250 \mu \mathrm{s} / \mathrm{div}$ )

(a)

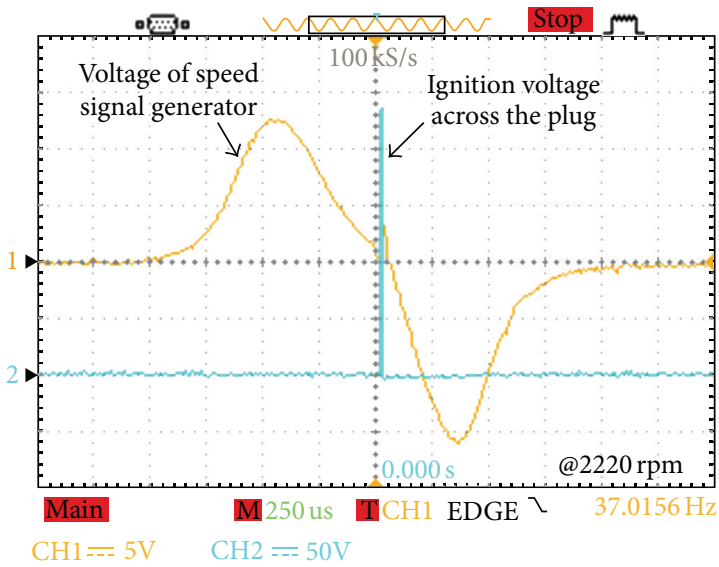

(upper trace: $5 \mathrm{~V} /$ div, lower trace: $5 \mathrm{kV} /$ div, time: $250 \mu \mathrm{s} / \mathrm{div}$ )

(b)

FIGURE 9: The waveforms of the ignition timing under the speed of about $2200 \mathrm{rpm}$ : (a) traditional plug and (b) the proposed plug.

proposed plug are in (3) and (7), respectively. If (7) is divided by (3), one can find

$$
E^{\prime}=\frac{A_{1}}{A_{2}} E_{C}
$$

Since $A_{2}<A_{1}$; then $E^{\prime}>E_{C}$. The $E_{C}$ is estimated by

$$
E_{C}=\frac{\Delta q}{\varepsilon_{0} A_{1}}=\frac{i(t) \Delta t}{\varepsilon_{0} A_{1}}=\frac{i(t) \Delta t^{\prime}}{\varepsilon_{0} A_{2}} .
$$

Thus, the following yields

$$
\Delta t^{\prime}<\Delta t
$$

This derivation shows that the electrical field $E^{\prime}$ is established faster than $E_{C}$ and the ignition charges are concentrated in a smaller cross-section. It results in an improvement of engine combustion efficiency. The voltages across the spark plug created by the proposed plug and traditional plug are 


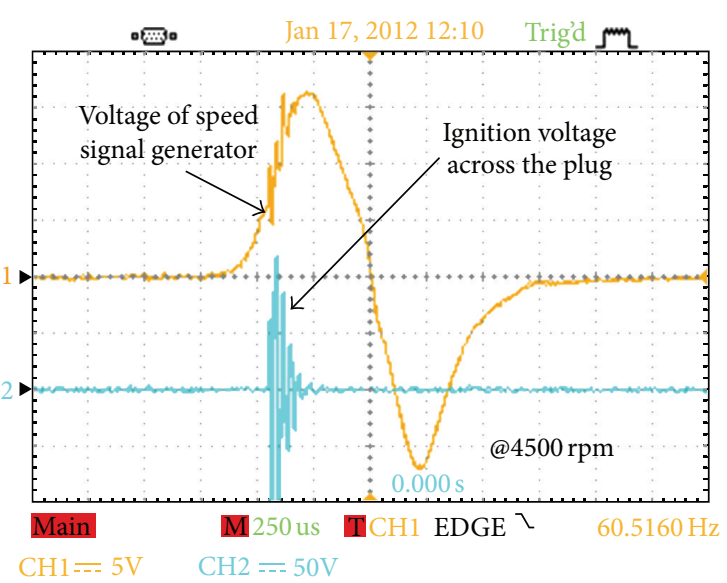

(upper trace: $5 \mathrm{~V} /$ div, lower trace: $5 \mathrm{kV} /$ div, time: $250 \mu \mathrm{s} / \mathrm{div}$ )

(a)

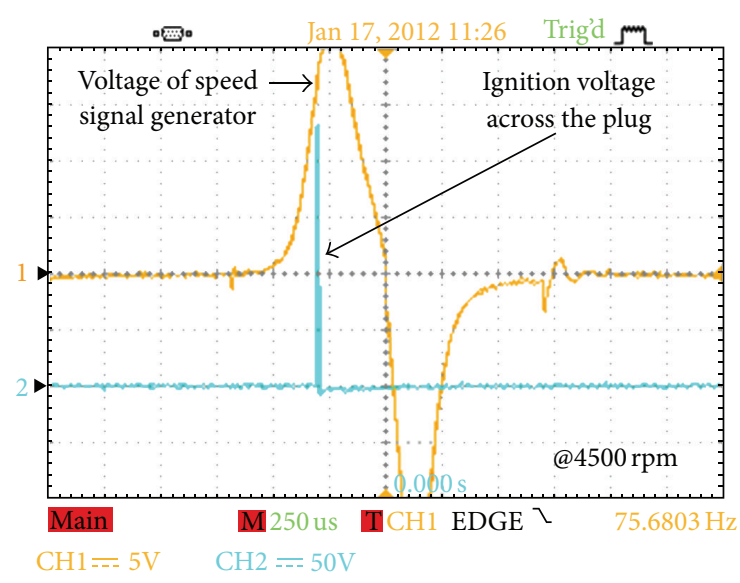

(upper trace: $5 \mathrm{~V} /$ div, lower trace: $5 \mathrm{kV} / \mathrm{div}$, time: $250 \mu \mathrm{s} / \mathrm{div}$ )

(b)

FIGURE 10: The waveforms of the ignition timing under the speed of about $4500 \mathrm{rpm}$ : (a) traditional plug and (b) the proposed plug.

shown in (6) and (10), respectively. As $E^{\prime}>E_{C}$, from (6) and (10), it can be obtained that

$$
V_{2}<V_{1} \text {. }
$$

This reveals that the proposed plug can reduce the ignition voltage as well as EMI issue.

\section{Experimental Results}

To verify the functionality of the proposed spark plug, realcar test is carried out, and practical measurement is fulfilled. In order to complete the contrast test, key parameters of the proposed novel dual-electrode plug and the traditional one are listed in the following. A corresponding figure is also illustrated in Figure 7.

(1) The radius of the positive electrode is $r=1.2 \mathrm{~mm}$.

(2) The distance between positive electrodes is $d=$ $1.4 \mathrm{~mm}$.

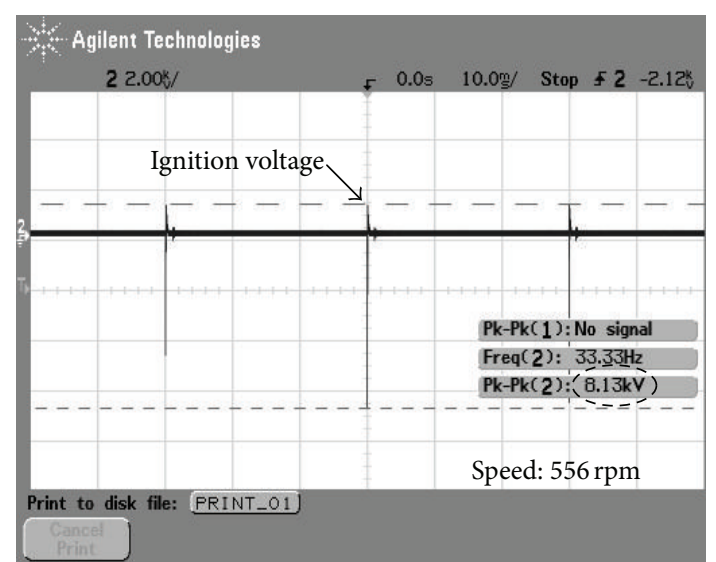

(voltage: $2 \mathrm{kV} /$ div, time: $10 \mathrm{~ms} /$ div)

(a)

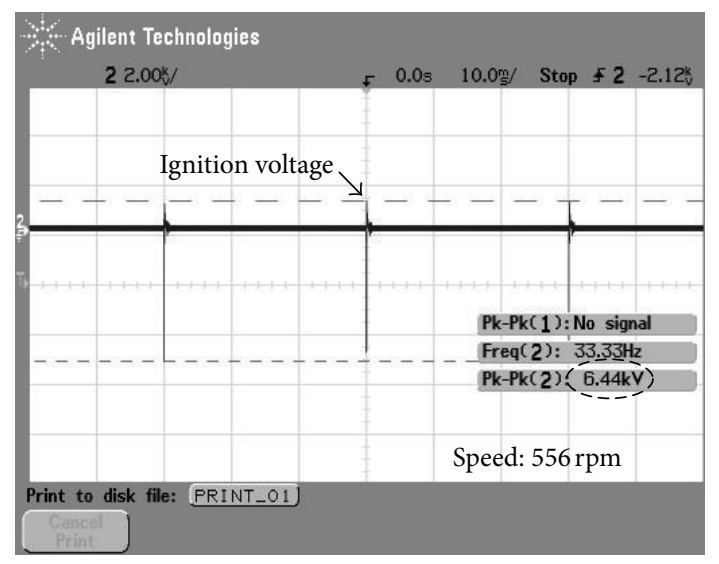

(voltage: $2 \mathrm{kV} /$ div, time: $10 \mathrm{~ms} /$ div)

(b)

FIgURE 11: The waveforms of the ignition voltages under the speed of about $556 \mathrm{rpm}$ : (a) traditional plug and (b) the proposed plug.

(3) The top cross section of positive electrode of the traditional plug $A_{1}=3.77 \mathrm{~mm}^{2}$.

(4) The top cross section of positive electrode of the proposed plug $A_{2}=2.40 \mathrm{~mm}^{2}$.

In the test, a flyback-type capacitor discharging igniter is used as the plug driver. Figures 8,9 , and 10 show that the proposed plug has the feature of less time delay at the vehicle speed close to $1620 \mathrm{rpm}, 2220 \mathrm{rpm}$, and $4500 \mathrm{rpm}$, respectively. Figures 11, 12, and 13 show the ignition voltages measured from traditional plug and the proposed plug. It can be found that the proposed plug needs much smaller ignition voltage than that of the traditional one at the speeds of 556 , 838 , and $1380 \mathrm{rpm}$, in turns.

\section{Conclusion}

In this paper, a novel dual-electrode spark plug for combustion engines is proposed, which can obtain an enhanced electric field to lower ignition voltage and EMI issue. As a result, fuel consumption and exhaust pollution can be readily 


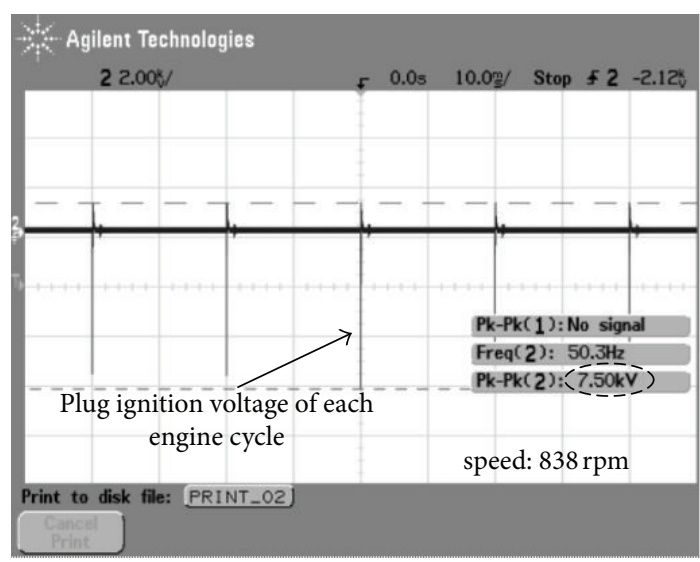

(voltage: $2 \mathrm{kV} / \mathrm{div}$, time: $10 \mathrm{~ms} / \mathrm{div}$ )

(a)

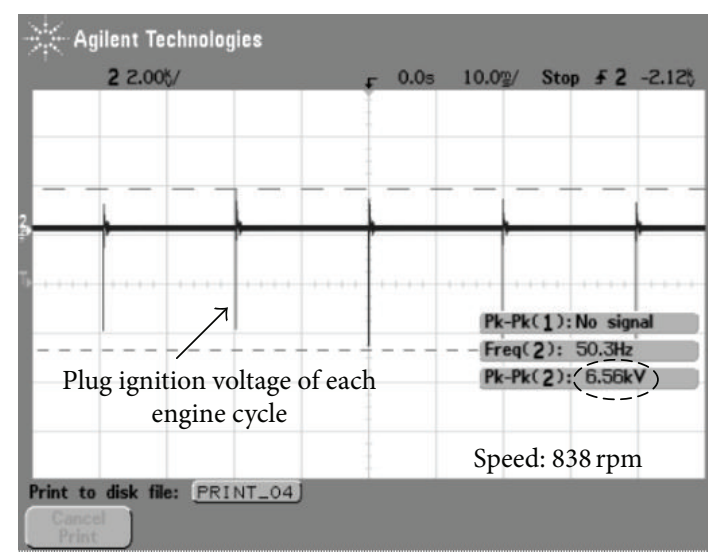

(voltage: $2 \mathrm{kV} /$ div, time: $10 \mathrm{~ms} / \mathrm{div}$ )

(b)

FIGURE 12: The waveforms of the ignition voltages under the speed of about $838 \mathrm{rpm}$ : (a) traditional plug and (b) the proposed plug.

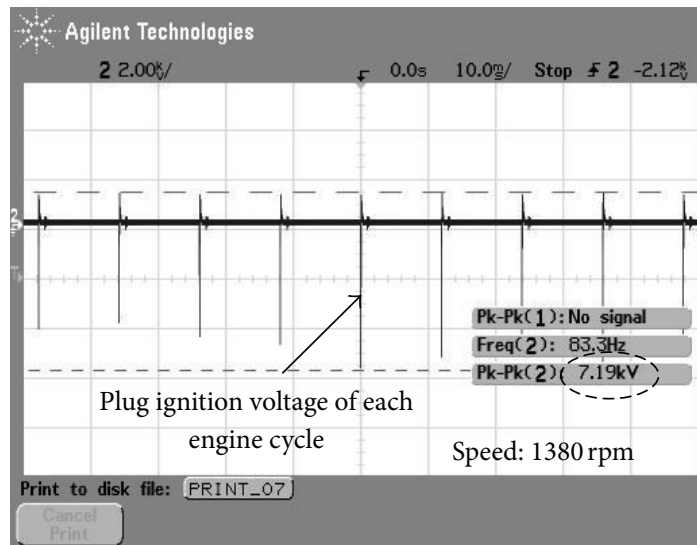

(voltage: $2 \mathrm{kV} / \mathrm{div}$, time: $10 \mathrm{~ms} / \mathrm{div}$ )

(a)

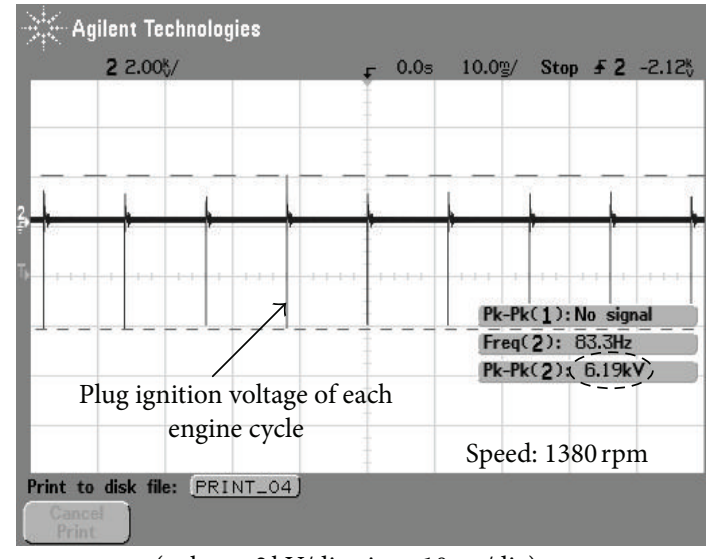

(voltage: $2 \mathrm{kV} / \mathrm{div}$, time: $10 \mathrm{~ms} / \mathrm{div}$ )

(b)

FIGURE 13: The waveforms of the ignition voltages under the speed of about $1380 \mathrm{rpm}$ : (a) traditional plug and (b) the proposed plug.

alleviated. The electric field built in the proposed plug and the corresponding ignition voltage are discussed by Gauss law and Faraday law. To verify the excellent performance of the plug, real-car test is carried out. The proposed plug and a traditional plug are installed in an engine vehicle in turn. At a different speed, the measured results reveal that the proposed plug can lead to lower ignition voltage and have exact igniting timing.

\section{References}

[1] R. Hawley, "Urban energy needs and the environment," Engineering Science and Education Journal, vol. 5, no. 2, pp. 89-95, 1996.

[2] J. B. Vance, B. C. Kaul, S. Jagannathan, and J. A. Drallmeier, "Output feedback controller for operation of spark ignition engines at lean conditions using neural networks," IEEE Transactions on Control Systems Technology, vol. 16, no. 2, pp. 214-228, 2008.
[3] E. Hellstrom, A. Stefanopoulou, and L. Jiang, "Cyclic variability and dynamical instabilities in auto-ignition engines with high residuals," IEEE Transactions on Control Systems Technology, vol. 21, no. 5, pp. 1527-1536, 2013.

[4] W. Langeslag, R. Pagano, K. Schetters, A. Strijker, and A. van Zoest, "VLSI design and application of a high-voltagecompatible SoC-ASIC in bipolar CMOS/DMOS technology for AC-DC rectifiers," IEEE Transactions on Industrial Electronics, vol. 54, no. 5, pp. 2626-2641, 2007.

[5] Z. J. Shen and S. P. Robb, "A dual-voltage self-clamped IGBT for automotive ignition applications," IEEE Electron Device Letters, vol. 22, no. 5, pp. 239-241, 2001.

[6] M. Jia, Q. Howard Zhang, and D. B. Min, "Pulsed electric field processing effects on flavor compounds and microorganisms of orange juice," Food Chemistry, vol. 65, no. 4, pp. 445-451, 1999.

[7] H. S. Bhat and B. Osting, "Kirchhoff's laws as a finite volume method for the planar Maxwell equations," IEEE Transactions on Antennas and Propagation, vol. 59, no. 10, pp. 3772-3779, 2011. 
[8] O. Ouchetto, H. Ouchetto, S. Zouhdi, and A. Sekkaki, "Homogenization of Maxwell's equations in lossy bi-periodic metamaterials," IEEE Transactions on Antennas and Propagation, vol. 61, no. 8, pp. 4214-4219, 2013.

[9] C.-T. Tsai and C.-L. Shen, "High efficiency current-doubler rectifier with low output current ripple and high step-down voltage ratio," IEEJ Transactions on Electrical and Electronic Engineering, vol. 8, no. 2, pp. 182-189, 2013.

[10] H. Yoshino, K. Sato, A. Tomago, and I. Yamauchi, "Development of a corona discharge detector for flyback transformers," IEEE Transactions on Consumer Electronics, vol. 23, no. 1, pp. 114-119, 1977.

[11] F. Forest, E. Labouré, T. A. Meynard, and J.-J. Huselstein, "Multicell interleaved flyback using intercell transformers," IEEE Transactions on Power Electronics, vol. 22, no. 5, pp. 16621671, 2007.

[12] N. P. Papanikolaou and E. C. Tatakis, "Minimisation of power losses in PFC flyback converters operating in the continuous conduction mode," IEE Proceedings, vol. 149, no. 4, pp. 283-291, 2002.

[13] R. Watson, F. C. Lee, and G. C. Hua, "Utilization of an activeclamp circuit to achieve soft switching in flyback converters," IEEE Transactions on Power Electronics, vol. 11, no. 1, pp. 162$169,1996$.

[14] C.-L. Shen and S.-H. Yang, "Multi-input converter with MPPT Feature for wind-PV power generation system," International Journal of Photoenergy, vol. 2013, Article ID 129254, 13 pages, 2013.

[15] C.-L. Shen and K.-K. Chen, "Single-stage coupled-inductor Sepic-type HB-LED driver with soft-switching for universal line input," Mathematical Problems in Engineering, vol. 2012, Article ID 593568, 17 pages, 2012.

[16] S. J. Beebe, P. M. Fox, L. J. Rec, K. Somers, R. H. Stark, and K. H. Schoenbach, "Nanosecond pulsed electric field (nsPEF) effects on cells and tissues: apoptosis induction and tumor growth inhibition," IEEE Transactions on Plasma Science, vol. 30, no. 1, pp. 286-292, 2002. 


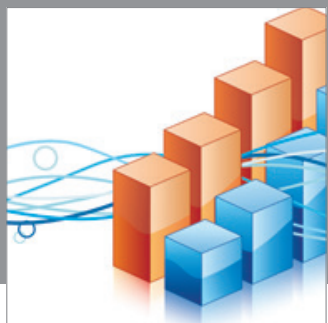

Advances in

Operations Research

mansans

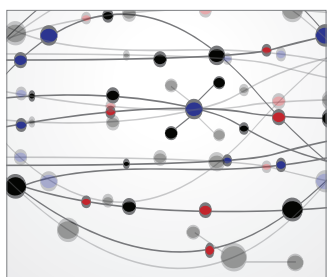

The Scientific World Journal
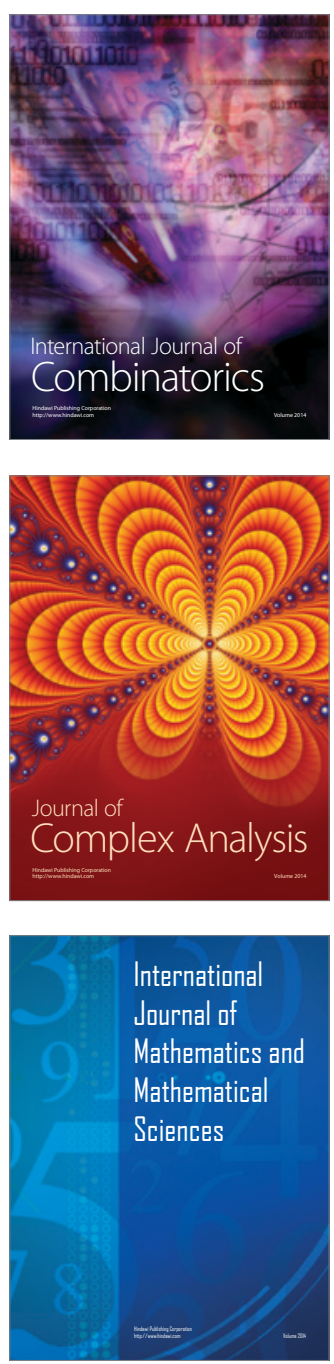
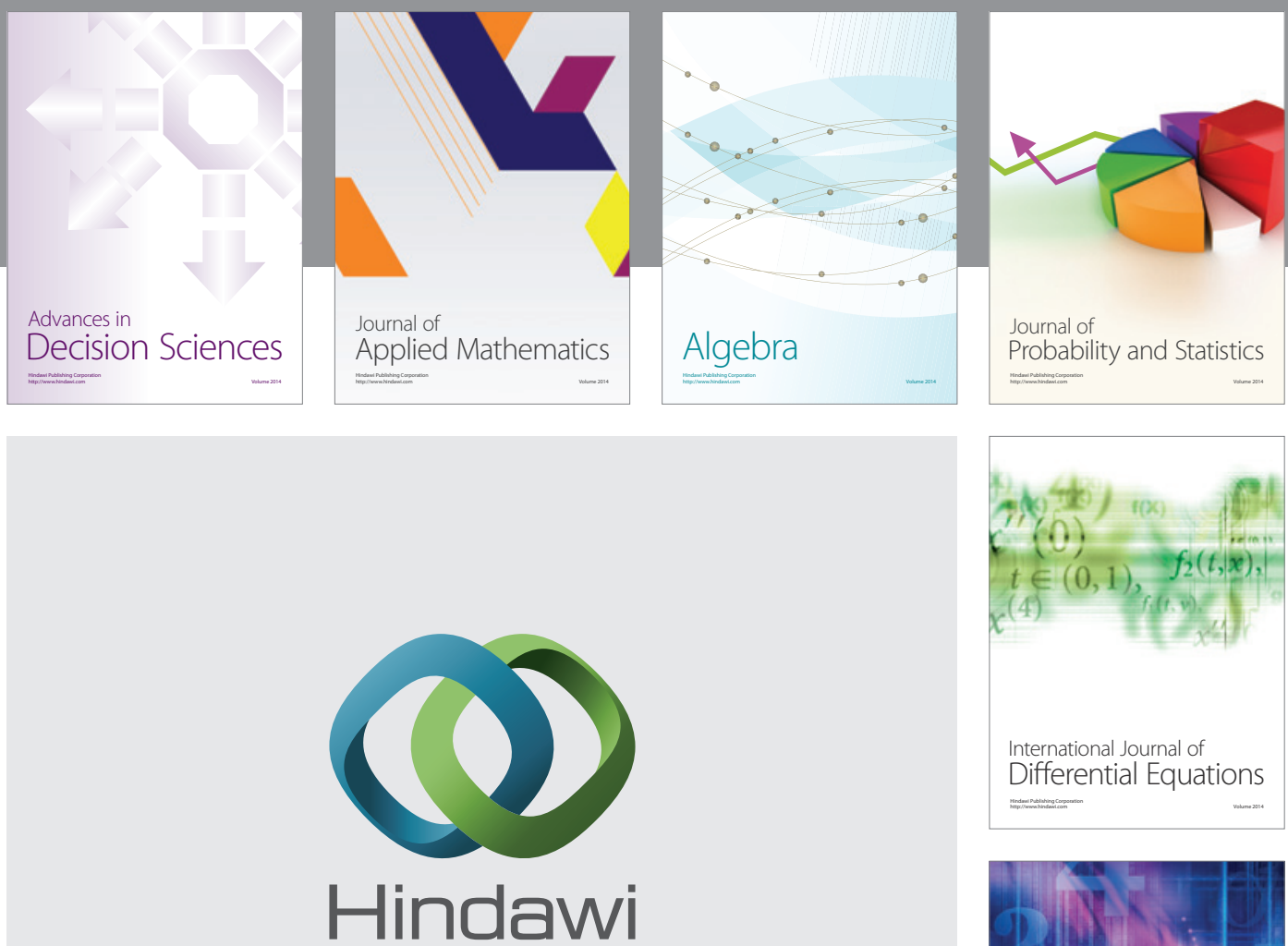

Submit your manuscripts at http://www.hindawi.com
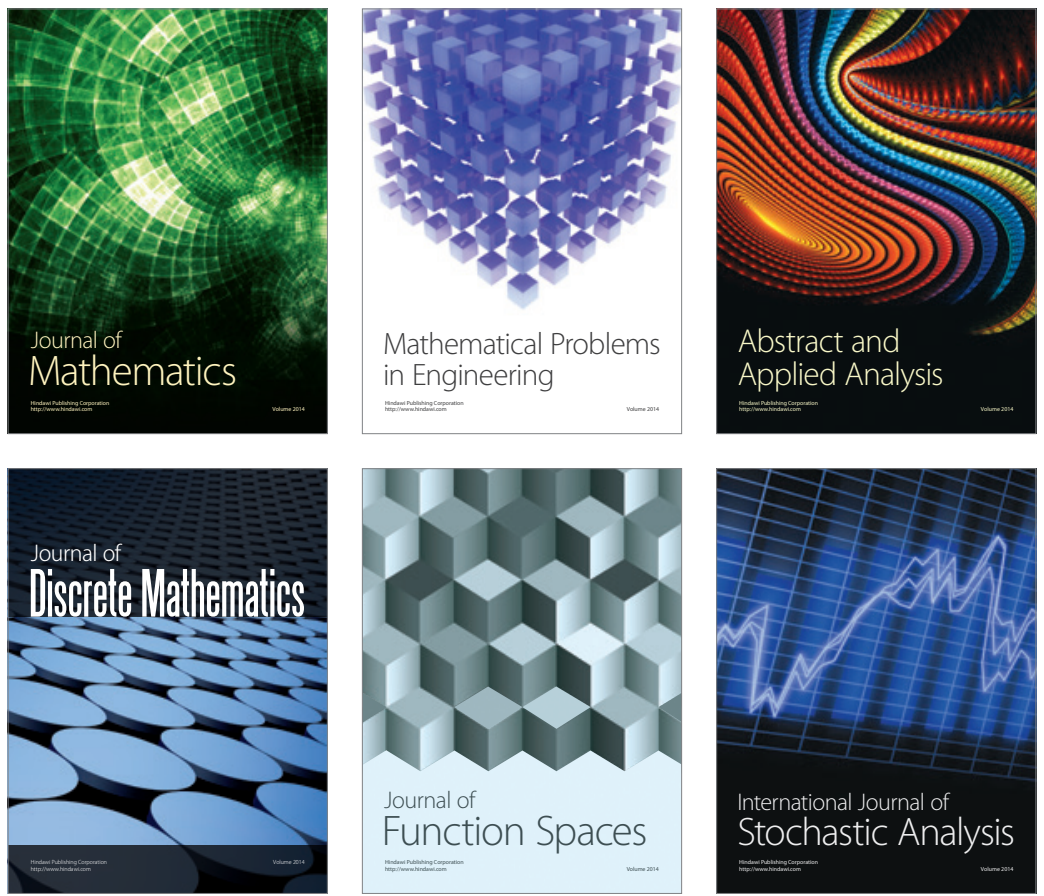

Journal of

Function Spaces

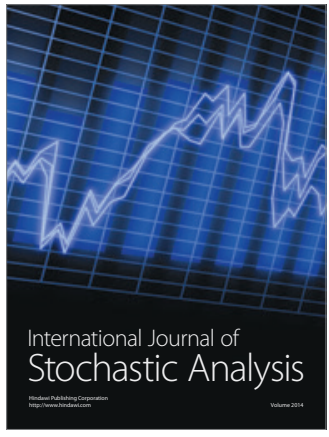

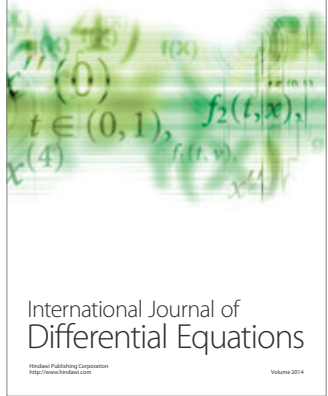
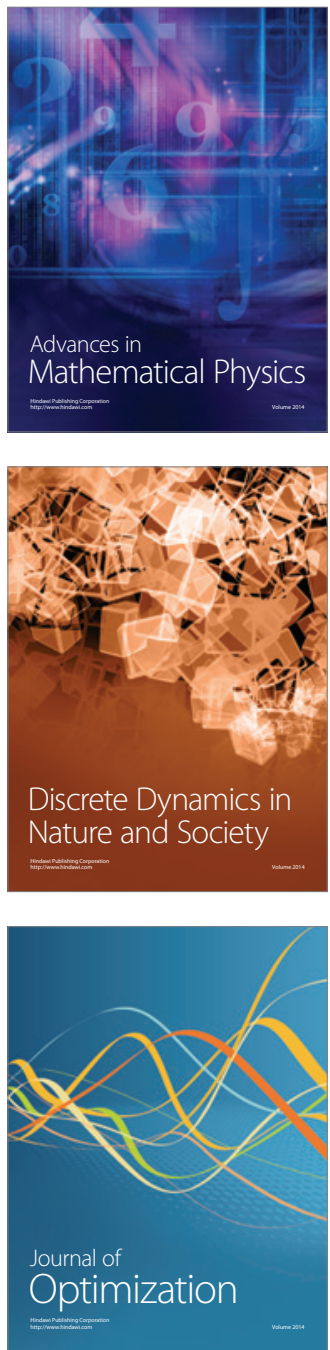